\title{
THE SPLITTING OF THE DOMAIN OF THE DEFINITION OF THE ELLIPTIC SELF-ADJOINT PSEUDODIFFERENTIAL OPERATOR
}

D.E. Shafranov, South Ural State University, Chelyabinsk, Russian Federation, shafranovde@susu.ac.ru

In this work we researched domain splitting of self-adjoint elliptic pseudodifferential operator. In particular the Laplace - Beltrami operator in the space of smooth differential $k$-forms defined on a smooth compact oriented Riemannian manifold without boundary be such operator. This result can be used in model with Sobolev type equations.

Keywords: differential $k$-forms; Riemannian manifold; Sobolev type model; the direct sum of subspaces.

\section{Introduction}

Now a days various mathematical models are widely investigated on the basis of Sobolev type equations of the form:

$$
L \dot{u}=M u,
$$

with an irreversible operator $L$ at the derivative [1]. Note, that researches are conducted as for abstract equations, as for particular applications of this kind [2]. There are qualitative and numerical analysis of solutions of these equations in various cases. We are interested in one aspect of the solvability of the Cauchy problem

$$
u(0)=u_{0}
$$

in the space of differential $k$-forms defined on a Riemannian manifold without boundary for equations of the form (1). That is the splitting of the domain of the definition of the operator $L \in \mathcal{L}(\mathfrak{U}, \mathfrak{F})$ into a direct sum of subspaces

$$
\mathfrak{U}=\mathfrak{U}^{0} \oplus \mathfrak{U}^{1},
$$

requiring in the relativity operators theory.

In the work [5] the special case of differential operators in the space of $k$-forms on the sphere was studied.

In the introduction we have formulated our problem. Then we have described its relationship with the mathematical models of Sobolev type. In the first part (preliminary information) we have given the definition of the space of differential $k$-forms on a manifold without boundary and have considered elements of Sviridyuk theory of $(L, p)$-bounded operators [1] and the theorem of Hodge-Kodaira about the splitting of such spaces [3]. The second part (main results) has presented the main result of the splitting of the domain of the definition elliptic self-adjoint operator and comments. 


\section{Preliminary Information}

Let $U$ and $F$ be Banach spaces and operators $L, M \in \mathcal{L}(U, F)$ are linear and bounded. Consider the $L$-resolvent of operator $M$ set $\rho^{L}(M)=\left\{\mu \in \mathbb{C}:(\mu L-M)^{-1} \in \mathcal{L}(F, U)\right\}$ and $L$-spectrum $\sigma^{L}(M)=\mathbb{C} \backslash \rho^{L}(M)$ of an operator $M$.

The operator function $(\mu L-M)^{-1}$ will be called $L$-resolvent of an operator $M$, and the operator function $R_{\mu}^{L}(M)=(\mu L-M)^{-1} L$ and $L_{\mu}^{L}(M)=L(\mu L-M)^{-1}$, the right and the left $L$-resolvent of operator $M$, respectively.

Definition 1. Operator $M$ is called bounded with respect to operator $L$ (shorter, $(L, \sigma)$ bounded) whenever

$$
\exists a \in \mathbb{R}_{+} \forall \mu \in \mathbb{C}:(|\mu|>a) \Rightarrow\left(\mu \in \rho^{L}(M)\right) .
$$

Operator $M$ is called $(L, p)$-bounded whenever it is $(L, \sigma)$ - bounded and the point $\infty$ - is a pole of order $p \in\{0\} \cup \mathbb{N} L$-resolvent of an operator $M$.

Let $\rho^{L}(M) \neq \oslash$. An Equation (1) is reduced to a couple of the equivalent equations

$$
\begin{aligned}
& R_{\delta}^{L}(M) \dot{u}=(\delta L-M)^{-1} M u, \\
& L_{\delta}^{L}(M) \dot{f}=M(\delta L-M)^{-1} f,
\end{aligned}
$$

where $\delta \in \rho^{L}(M)$. Both equations will be considered as specific interpretations of the equation

$$
A \dot{v}=B v,
$$

where the operators $A \in \mathcal{L}(W)$, and $W$ - some Banach space. Solution of the equation (6) is a vector function $v \in C^{\infty}(\mathbb{R}, W)$ satisfying the equation (6).

Definition 2. The mapping $V \in C^{\infty}(\mathbb{R}, \mathrm{L}(W))$ is called the resolving analytical group of the equation (6), if

(i) $V^{s} V^{t}=V^{s+t}$ for all $s, t \in \mathbb{R}$;

(ii) for every $v_{0} \in W$ vector-valued function $v(t)=V^{t} v_{0}$ is the solution of the equation (6).

Theorem 1. [1] Let an operator $M$ is $(L, p)$ - bounded. Then there are the resolving analytical groups of equations (4) and (5), represented by integrals of Dunford - Taylor

$$
\begin{aligned}
U^{t} & =\frac{1}{2 \pi i} \int_{\Gamma} R_{\mu}^{L}(M) e^{\mu t} d \mu, \\
F^{t} & =\frac{1}{2 \pi i} \int_{\Gamma} L_{\mu}^{L}(M) e^{\mu t} d \mu,
\end{aligned}
$$

where the contour $\Gamma$ bounds area containing the $\sigma^{L}(M)$.

Groups (7), (8) have units

$$
U^{0}=\frac{1}{2 \pi i} \int_{\Gamma} R_{\mu}^{L}(M) d \mu=P, \quad F^{0}=\frac{1}{2 \pi i} \int_{\Gamma} L_{\mu}^{L}(M) d \mu=Q .
$$

Let the kernels and images of these semigroups $\operatorname{ker} P=\mathfrak{U}^{0}, \operatorname{im} P=\mathfrak{U}^{1}, \operatorname{ker} Q=\mathfrak{F}^{0}$, $\operatorname{im} Q=\mathfrak{F}^{1}$. 
Let $\Omega_{n}$ be a smooth compact oriented Riemannian manifold without boundary. Spaces of smooth differential $k$-forms defined on the manifold $\Omega_{n}$ we denote as the $H_{k}=H_{k}\left(\Omega_{n}\right), \quad k=0,1, \ldots, n$. In the spaces $H_{k}$ the Laplace - Beltrami operator $\Delta=d \delta+\delta d$ was defined, where $d$ - an operator of an exterior differentiation of $k$-forms, $\delta=(-1)^{n(k+1)+1} * d *-$ an adjoint operator to an operator $d$, and $*$ - Hodge operator. Let $H_{k d}=d \delta\left[H_{k}\right], H_{k \delta}=\delta d\left[H_{k}\right], H_{k \Delta}=\operatorname{ker} \Delta, k=0,1, \ldots, n$.

The scalar product in the space $H_{k}, k=0,1, \ldots, n$ defined by the formula

$$
(\xi, \eta)_{0}=\int \xi \wedge * \eta, \text { where } \xi, \eta \in H_{k}
$$

and the corresponding norm is denoted $\|\cdot\|_{0}$. The replenishment of the space $H_{k}$ in this norm is denoted $\mathfrak{H}_{k}^{0}$. The replenishment lineals $H_{k d}, \quad H_{k \delta}, \quad H_{k \Delta}$ on it will be denoted by $\begin{array}{llll}\mathfrak{H}_{k d}^{0} & \mathfrak{H}_{k \delta}^{0} & \mathfrak{H}_{k \Delta}^{0}\end{array}$

Theorem 2. [3] (Hodge - Kodaira) For every $k=0,1, \ldots, n$ there is a splitting of the space $\mathfrak{H}_{k}^{0}$ in the orthogonal direct sum

$$
\mathfrak{H}_{k}^{0}=\mathfrak{H}_{k d}^{0} \oplus \mathfrak{H}_{k \delta}^{0} \oplus \mathfrak{H}_{k \Delta}^{0}
$$

moreover the dimension of the space $\mathfrak{H}_{k \Delta}^{0}$ is finite.

Enter in accordance with the following formulas

$$
(\xi, \eta)_{1}=(-\Delta \xi, \eta)_{0}+(\xi, \eta)_{0} ;(\xi, \eta)_{2}=(\Delta \xi, \Delta \eta)_{0}+(\xi, \eta)_{1},
$$

two more scalar products in the space $H_{k}, k=0,1, \ldots, n$, and denote the relevant rules $\|\cdot\|_{1}$ and $\|\cdot\|_{2}$, respectively. The replenishment of the space $H_{k}$ by these rules denote $\mathfrak{H}_{k}^{1} \mathfrak{H}_{k}^{2}$.

Consider an orthogonal projector $P_{\Delta}$, ker $P_{\Delta}=\mathfrak{H}_{k \Delta}^{0}$ in $\mathfrak{H}_{k}^{0}$. It will be an orthogonal projector and in $\mathfrak{H}_{k}^{1} \mathfrak{H}_{k}^{2}$, moreover by virtue of the finite their kernels coincide and $\mathfrak{H}_{k \Delta}^{0}=\mathfrak{H}_{k \Delta}^{1}=\mathfrak{H}_{k \Delta}^{2}$.

Let the space $\mathbf{H}_{\mathbf{k}}^{\mathbf{l}}=\left(\mathfrak{H}_{k \Delta}^{l}\right)^{\perp}, l=0,1,2$ ( that is an orthogonal adjoint to harmonic $k$-forms). The spaces $\mathbf{H}_{\mathbf{k}}^{\mathrm{i}}, i=1,2$ - Banach, moreover by virtue of by the continuity and density of attachments

$$
\mathbf{H}_{\mathrm{k}}^{0} \subset \mathbf{H}_{\mathrm{k}}^{1} \subset \mathbf{H}_{\mathrm{k}}^{2}
$$

and the finiteness of the rank of the operator $P_{k \Delta}$ and $k=0,1, \ldots, n$ we have the following Corollary 1. [4] For every $k=0,1, \ldots, n$ there are splitting spaces

$$
\mathbf{H}_{\mathrm{k}}^{\mathrm{i}}=\mathbf{H}_{\mathrm{k} \Delta}^{\mathrm{i} 1} \oplus \mathbf{H}_{\mathrm{k} \Delta}
$$

where $\mathbf{H}_{\mathbf{k} \boldsymbol{\Delta}}^{\mathrm{i} 1}=\mathbf{I}-P_{k \Delta} \mathbf{H}_{\mathbf{k} \boldsymbol{\Delta}}, i=1,2$. 


\section{Main Results}

Let $\Omega_{n}$ is a smooth compact oriented Riemannian manifold without boundary. Using the preliminary information, we define

$$
\mathfrak{U}=\bigoplus_{k=0}^{n} \mathbf{H}_{\mathbf{k}}^{\mathbf{2}}, \mathfrak{F}=\bigoplus_{k=0}^{n} \mathbf{H}_{\mathbf{k}}^{\mathbf{0}}
$$

The spaces $\mathfrak{U}$ and $\mathfrak{F}$ are real vector bundles of differential $k$-forms on a manifold $\Omega_{n}$.

Let $U=C^{\infty}(\mathfrak{U}), \quad F=C^{\infty}(\mathfrak{F})$ vector space of smooth sections of $\mathfrak{U}, \mathfrak{F}$, respectively.

Definition 3. An linear differential operator $L$ of order $l$, from $U$ to $F$ - is a linear map from $U$ to $F$. Operator $L$ is called elliptic if it is elliptical locally (in each trivialization).

Theorem 3. Let $L$ be an linear elliptic self-adjoint differential operator. Then the spaces $U$ and $F$ decompose into direct sums

$$
\begin{aligned}
& F=\operatorname{im} L \oplus \operatorname{ker} L^{*}, \\
& U=\operatorname{im} L^{*} \oplus \operatorname{ker} L .
\end{aligned}
$$

\section{References}

1. Sviridyuk G.A., Fedorov V.E. Linear Sobolev Type Equations and Degenerate Semigroups of Operators. Utrecht, Boston, Tokyo, Köln, VSP, 2003.

2. Sviridyuk G.A., Zagrebina S.A. Nonclassical Mathematical Physics Models. Bulletin of the South Ural State University. Series: Mathematical Modelling, Programming and Computer Software, 2012, no. 40 (299), issue 14, pp. 7-18. (in Russian)

3. Warner F.W. Foundations of Differentiable Manifolds and Lie Groups. New York, Springer, 1983. DOI: 10.1007/978-1-4757-1799-0.

4. Shafranov D.E., Shvedchikova A.I. The Hoff Equation as a Model of Elastic Shell. Bulletin of the South Ural State University. Series: Mathematical Modelling, Programming and Computer Software, 2012, vol. 18(277), issue 12, pp. 77-81. (in Russian)

5. Shafranov D.E. [One Sobolev Type Model in the Space of Differential $k$-forms on the Sphere]. Nauka YuUrGU: Materialyi 66-y nauchnoy konferentsii sektsii estestvennyih nauk [SUSU Science: Proceedings of 66th Scientific Conference of the Section of Natural Sciences]. Chelyabinsk, Publishing center of SUSU, 2014, pp. 234-238. (in Russian)

Dmitry E. Shafranov, candidate of physical and mathematical sciences, associate professor, department of equation of mathematical physics, South Ural State University, Chelyabinsk, Russian Federation, shafranovde@susu.ac.ru.

Received August 1, 2015 


\title{
РАСЩЕПЛЕНИЕ ОБЛАСТИ ОПРЕДЕЛЕНИЯ ЭЛЛИПТИЧЕСКОГО САМОСОПРЯЖЕННОГО ПСЕВДОДИФФЕРЕНЦИАЛЬНОГО ОПЕРАТОРА
}

\section{Д.Е. Шафранов}

\begin{abstract}
В работе исследовано расщепление области определения эллиптического самосопряженных псевдодифференциального оператора. В частности оператор Лапласа - Бельтрами, в пространстве гладких дифференциальных $k$-форм, определенных на гладком компактном ориентированном римановом многообразии без края относится к таковым. Данный результат можно использовать в теории моделей соболевского типа.

Ключевые слова: дифференциальные $k$-формы; риманово многообразие; модели соболевского типа; прямая сумма подпространств.
\end{abstract}

\section{Литература}

1. Sviridyuk, G.A. Linear Sobolev Type Equations and Degenerate Semigroups of Operators / G.A. Sviridyuk, V.E. Fedorov. - Utrecht; Boston; Tokyo; Köln: VSP, 2003.

2. Свиридюк, Г.А. Неклассические модели математической физики / Г.А. Свиридюк, С.А. Загребина // Вестник ЮУрГУ. Серия: Математическое моделирование и программирование. - 2012. - № 40 (299), вып. 14. - С. 7-18.

3. Warner, F.W. Foundations of Differentiable Manifolds and Lie Groups F.W. Warner. - New York: Springer, 1983.

4. Шафранов, Д.Е. Уравнение Хоффа как модель упругой оболочки / Д.Е. Шафранов, А.И. Шведчикова // Вестник ЮУрГУ. Серия: Математическое моделирование и программирование. - 2012. - № 18 (277), вып. 12. - С. 77-81.

5. Шафранов, Д.Е. О моделях соболевского типа в пространстве дифференциальных $k$-форм на сфере / Д.Е. Шафранов // Наука ЮУрГУ: материалы 66-й научной конференции секции естественных наук. - Челябинск: Издательский центр ЮУрГУ, 2014. - С. 234-238.

Шафранов Дмитрий Евгенвевич, кандидат физико-математических наук, доиент, кафедра уравнений математической физики, Южн-Уральский государственный университет (е. Челябинск, Российская Федераиия), shafranovde@susu.ac.ru.

Поступила в редакиию 1 августа 2015 г. 